\title{
Uma reflexão sobre os múltiplos sentidos da docência em saúde*
}

Gilson Saippa Oliveira ${ }^{1}$

Lilian Koifman²

\section{Introdução}

Os desafios da formação dos profissionais de saúde, que sejam capazes de responder, em suas ações cotidianas, aos desafios ético-políticos do SUS, têm orientado os debates e formulações de políticas públicas, arranjos tecnoperacionais, e encontram materialização: nos balizamentos normativos presentes nos Relatórios da Xa ${ }^{\mathrm{X}} \mathrm{XI}^{\mathrm{a}}$ e da XII ${ }^{\mathrm{a}}$ Conferências Nacionais de Saúde, na Norma Operacional de Recursos Humanos para o SUS (NOB/RH-SUS), nas Diretrizes Curriculares Nacionais para os cursos universitários da área da saúde ( $D C N$ 's), e nas diferentes políticas do Ministério da Saúde que tratam do tema (Brasil, 2004b; 2001).

Os princípios legais e normativos ganham materialidade no formato de arranjos e dispositivos indutivos de políticas de formação nas estratégias conjuntas ou isoladas do Ministério da Saúde (MS) e da Educação (MEC). Dentre elas, destacam-se: o Programa de Incentivo às Mudanças Curriculares para as Escolas Médicas (PROMED), o Programa de Educação Permanente (Polos de Educação Permanente) e, mais recentemente, o Programa Nacional de Reorientação do profissional em Saúde (Pró-Saúde) (Brasil, 2007; 2005; 2004a; 2003; 2002).

Explicita-se de maneira bastante clara, em tais relatórios e dispositivos institucionais, a necessidade de uma política de Recursos Humanos para o SUS, pois a sua inexistência propicia um modelo de formação, tanto de profissionais de nível Superior quanto de Médio, centrado no uso intensivo de tecnologias e especialização. Alerta-se que esse processo deve concentrar-se na formação de profissionais que tenham clareza de sua inserção e desempenho no processo de trabalho em saúde, conscientes do compromisso com a humanização e compreensão da diversidade sociocultural da sociedade brasileira, bem como dos aspectos éticos do SUS (Ceccim, 2005).

A partir de uma concepção ampla de saúde, as políticas propõem mudanças de modelos metodológicos, abandonando a ênfase nos conteúdos para adotar movimentos que estimulam a aprendizagem ativa. Como proposta, busca-se, assim, superar a dicotomia entre teoria e prática, valorizando o trabalho articulado aos serviços, com identificação da capacidade de desenvolvimento da atenção, centrada na prevenção, promoção, proteção e reabilitação, em nível individual e coletivo. O modelo adotado propõe: valorizar a tomada de decisões,

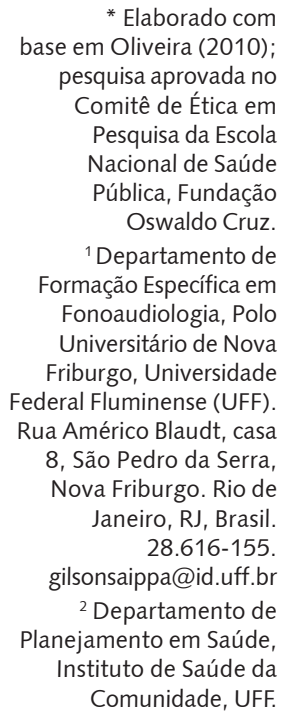

* Elaborado com base em Oliveira (2010); pesquisa aprovada no Comitê de Ética em Pesquisa da Escola Nacional de Saúde Pública, Fundação Oswaldo Cruz. ${ }^{1}$ Departamento de Formação Específica em Fonoaudiologia, Polo Universitário de Nova Friburgo, Universidade Federal Fluminense (UFF).

Rua Américo Blaudt, casa 8, São Pedro da Serra, Nova Friburgo. Rio de Janeiro, RJ, Brasil. 28.616-155.

gilsonsaippa@id.uff.br ${ }^{2}$ Departamento de Planejamento em Saúde, Instituto de Saúde da Comunidade, UFF. 
UMA REFLEXÃO SOBRE OS MÚLTIPLOS SENTIDOS ...

comunicação, liderança, administração e o gerenciamento dos processos de trabalho, produção de informação e planejamento de ações, habilitando o profissional para o trabalho em equipe e a produção da atenção integral (Haddad, Ristoff, Passarela, 2006; Batista, 2004).

Tais balizamentos e orientações normativas são apropriados e interpretados pelos docentes universitários, no cotidiano dos processos de formação, de formas diversas. Tal apropriação revela que esses espaços se apresentam como lugares de produção, onde se misturam e (re) produzem sentidos que podem provir de fontes diversas e contraditórias.

A compreensão desse processo de (re) apropriação e (re) afirmação ou negação de sentidos tem exigido das diferentes comunidades interpretativas - sejam elas pesquisadores do campo, operadores das políticas públicas ou gestores das escolas - a produção de um deslocamento operacional, conceitual e epistêmico que se afasta das perspectivas prescritivas de comportamento e que se encerra nas desejáveis qualidades da docência. Essas perspectivas ganham formato nos processos internos e externos às instituições de ensino a partir de projetos de sensibilização, capacitação e profissionalização da docência em saúde (Nóvoa, 2007; 1997; Moita, 2007; Cunha, 2006; Brandt Ribeiro, 1999; Therrien, 1997).

Segundo Faria e Casagrande (2004), verifica-se que, no centro dos debates e discussões sobre os rumos da educação, encontramos o docente: sua formação, desempenho e o desenvolvimento profissional. Nos tempos atuais, a docência universitária deve propiciar a formação do profissional cidadão, devendo se alterarem os projetos pedagógicos que privilegiam a formação de técnicos profissionais. Ainda segundo os autores, apesar dessa constatação, pouca atenção tem sido voltada à formação e desenvolvimento de docentes de nível superior no Brasil.

Em estudo recente, Araujo, Batista e Gerab (2011) analisam artigos publicados em periódicos nacionais que abordam a formação docente em saúde. Das 76 publicações levantadas, a análise "evidencia as necessidades dos pesquisadores de compreensão do processo de mudança na área, permitindo delinear diretrizes para a elaboração de um projeto de desenvolvimento docente" (Araujo, Batista e Gerab, 2011, p.486).

O trabalho das autoras possibilitou delinear quatro eixos para um processo de formação docente em saúde: compreensão histórica e política da educação superior em saúde; discussão e análise dos modelos hegemônicos e de modelos considerados inovadores no campo da graduação em saúde; estudo crítico das Diretrizes Curriculares Nacionais; análise crítica do papel do professor da área da saúde e da importância da reflexão sobre a prática.

\section{A docência e seus múltiplos sentidos}

O exercício da docência revela um conjunto de saberes que compõem o universo de significação e sentidos que se revelam, (re) produzem de acordo com as mediações e as coordenadas políticoadministrativas que regulam o sistema de ensino, não necessariamente ligados ao exercício imediato da docência (Moreira, 2007; Otero Ribeiro, 2004; Morosini, 2000).

O trabalho docente se apoia em conhecimentos díspares que se revelam no seu exercício, como experiência de identidade e alteridade, onde se misturam aspectos pessoais, sentimentos do docente que se descobrem e se constroem no próprio trabalho e se orientam pelos posicionamentos desses agentes no interior do campo científico e acadêmico (Tardif, 2005; Tardif, Lessard, 2005; Borges, 2004).

Nesse complexo campo de interações, as inserções ocorrem a partir de quatro diferentes formas: profissionais de várias áreas de formação que exercem a docência em tempo integral; os que atuam nas suas profissões de origem e se dedicam ao magistério apenas algumas horas por semana; docentes das áreas específicas de pedagogia e licenciaturas que atuam, simultaneamente, nas graduações dos cursos de licenciatura e, também, no Ensino Fundamental e Médio e, por último, os profissionais da área de educação que desenvolvem suas atividades em tempo integral na universidade (Behrens, 2000).

Cada trajetória, nos diversos espaços relacionais, assume contornos diversificados na construção da identidade e na atuação, que podem ser, por sua vez, tipificadas por fases que exprimem tendências gerais do ciclo da vida dos professores como um processo específico que comporta uma sequência não linear de acordo com o tempo de carreira. Nas diferentes formas de vinculação, trajetórias e fases, cada docente se apropria de saberes a partir de um modo de conhecer dinâmico, menos sistematizado ou 
rigoroso, articulado a diferentes formas de fazer, não se prendendo a normas rígidas de validação (Fiorentini et al., 2007; Huberman, 2007).

O confronto entre a dupla exigência de aprender e, ao mesmo tempo, ser reconhecido pelos outros, faz com que cada docente construa sua identidade em negociação permanente com o processo de comunicação ou de socialização, de pertencimento e de relação, que são capazes de produzir efeitos simultaneamente estáveis e provisórios, biográficos e estruturais, que dependem tanto dos julgamentos dos outros como das suas próprias orientações e autodefinições (Dubar, 2005).

A articulação entre as duas transações internas (subjetivas) e externas (objetivas) constitui a chave da relação entre as identidades herdadas, aceitas ou recusadas e as identidades visadas, em continuidade ou em ruptura com as precedentes. As diferentes articulações entre condições objetivas, quando confrontadas com as estruturas subjetivas, ocorrem através de duas formas de construção: a identidade para si e a identidade para o outro, como resultado, a um só tempo, estável e provisório, individual e coletivo, subjetivo e objetivo, biográfico e estrutural (Dubar, 2005).

A trajetória da docência imprime, em quem a exerce, uma espécie de saber-fazer hologramático, que se revela pela associação entre pensamento e ação, entre fazer e saber, entre saber e ser, que pode produzir práticas diferentes das existentes e constitui certa epistéme cotidiana implícita nas ações dos agentes, sendo, portanto, definido como um saber incoerente (contraditório) de suas determinações relacionais e assume a conformação do costume, conservadorismo e continuidade, mas, ao mesmo tempo, tem a capacidade de produzir outras práticas (Morin, 1998).

Cada docente vivencia e incorpora estoques de comportamento a partir de movimentos múltiplos de relação e reconhecimento perante os grupos (família, escola, associação, igreja etc.), e podem ser simultaneamente aluno (a), filho (a), colega ou amante, colega de trabalho ou trabalhador, membro atuante de uma associação, fiel de uma igreja (Elias, 1994).

Na produção de sentidos, acúmulos e rupturas que ocorrem no microcosmo do campo universitário, cada docente busca a construção de monopólios, distinções e, sobretudo, ocupação de espaços mais prestigiosos que funcionam como se fossem bancos de crédito simbólicos. Seu valor, na maior parte dos campos de conhecimento, baseia-se numa mescla entre a participação nas atividades de pesquisa, incluindo as publicações e participações em eventos qualificados, e na legitimidade que constrói no exercício profissional (Sousa Santos, 1996; Bourdieu, 1988; 1968).

Para Costa (2010), a partir de pesquisa realizada com professores de um curso de Medicina no Brasil, fica claro que os professores estudados aprenderam a sê-lo mediante um processo de socialização, em parte, intuitiva, autodidata, ou seguindo o modelo daqueles que foram considerados bons professores. $\mathrm{Na}$ mesma pesquisa, a autora salienta que, a partir das falas dos entrevistados, os saberes adquiridos através da experiência profissional fundamentam a competência docente. Outro ponto é a pouca valorização dada pela instituição à formação pedagógica do professor de medicina. Isso pode ser atribuído ao desmerecimento da atividade de ensino nas universidades, onde os estímulos para a atuação e os critérios de progressão na carreira têm se fundamentado mais na produção científica que no exercício da docência (Costa, 2010).

Neste universo de significações e disputas, espera-se que cada docente tenha domínio do campo científico de sua área de formação profissional que legitime esse saber na prática. A formação pedagógica representa valor menor frente aos diferentes desenhos contratuais e relacionais que produzem vínculos diferenciados com o ensino, a pesquisa e a extensão, e definem a dedicação exclusiva ou não à universidade (Cortesão, 2002; Lucarelli, 2000). Um bom exemplo desse universo pode ser visto nos sistemas de avaliação docente, maciçamente implantados no Brasil, que valorizam a produção através de artigos publicados em revistas indexadas. A carga horária dispensada em aulas, na graduação e/ou pós-graduação, é computada de forma numérica, quantitativa. Não existem instrumentos de avaliação da qualidade das aulas, sejam as mesmas proferidas em campo (e/ou práticas - típica situação que ocorre na área de saúde) ou em salas de aula (teóricas).

Por outro lado, no modelo de valorização simbólica, cada docente é medido pelo tamanho de seu gabinete, número proporcional de contratos de pesquisa obtidos e quantidade de instrumentos e equipamentos de pesquisa disponíveis que definem não só o perfil de acesso e sua permanência nas instituições, mas, fundamentalmente, a sua carreira (Japiassú, 1997). 
UMA REFLEXÃO SOBRE OS MÚLTIPLOS SENTIDOS ...

O acúmulo de créditos favorece a obtenção de poderes administrativos e políticos. A conversão de um tipo de capital em outro ocorre entre aqueles que ocupam posições de prestígio junto à estrutura acadêmica, além da participação em associações científicas de expressão nacional e internacional, assumindo a forma do prestígio pessoal, segundo os diferentes campos de conhecimento e instituições, e manifesta-se na maneira como cada agente é reconhecido nos chamados "colégios de invisíveis" (Bourdieu, 2004).

Na composição do capital de cada docente, no interior do campo universitário, constitui-se a partir de duas formas: a primeira delas se revela pela participação em pesquisas, publicações, comissões de avaliação, comitês organizadores de congressos científicos, especialmente os mais relevantes de cada campo e subcampo do conhecimento. A segunda é composta, sobretudo, pelas estratégias políticas específicas, como: orientação de dissertações e teses, participação em bancas de concursos e de teses, realização de consultorias e ocupação de cargos na administração universitária que agregam valor e aumentam a composição total de capitais no interior do universo acadêmico (Bourdieu, 2004).

$\mathrm{Na}$ busca de produção de monopólios da competência, os docentes utilizam um conjunto de manobras estratégicas que não só garantam, mas, fundamentalmente, aumentem o seu reconhecimento entre os pares. Essas manobras ocorrem num campo saturado de linhas de força produzidas por diversos outros competidores que também objetivam reconhecimento, através de outro conjunto de manobras (Bourdieu, Wacquant, 2008).

As citadas manobras possibilitam a instauração de novas linhas de força, demonstrando que o sentido do jogo produzido e valorizado pelo conjunto de agentes ocorre num universo de temporalidades diacrônicas, que asseguram a conformação de maneiras de se perceber, julgar, valorizar o mundo, e servem como conformadores do modo de agir de cada agente, estruturando suas ações (Bourdieu, 2005; 2001).

Esse jogo de posicionamentos torna-se público nas práticas institucionais com seu conjunto de normas, rotinas e processos decisórios, portanto é impossível identificar tais saberes sem relacioná-los ao habitus incorporado, na trajetória pessoal e no cotidiano do seu trabalho (Ronzani, 2007; Pimenta, Anastasiou, 2005).

Neste processo relacional e de disputa, se produzem diferentes formas de se recriar o passado através de uma temporalidade que materializa o pedagógico, pressupondo conhecimentos técnicos, sensibilidade e posicionamento valorativo sobre os objetivos. Configuram-se como potencialmente favoráveis à criação de dispositivos pedagógicos diferenciados nos contextos onde exercem a sua atividade e, por extensão, forjam sua própria identidade (Saippa-Oliveira, Koifman, 2011; Cortesão, 2002).

\section{Considerações}

Ao considerarmos a complexidade e caráter inacabado que a docência universitária apresenta, acreditamos que formuladores e agentes do campo devem se aproximar dos estudos e olhares que busquem a produção de informações sobre a composição dos saberes que potencializam a geração de seus esquemas de percepção.

Esses esquemas de percepção revelam sua capacidade de reinterpretação de saberes, que ganham contorno e tonalidades distintas, dependendo da formação identitária, que ocorrem por intermédio de diversos ritos de passagem (na família, escola, religião, serviço militar, esportes, grupos e espaços de relação, profissão, trabalho etc.). Dessa forma, nos parece pertinente que a agenda reformista da formação em saúde considere, no seu cotidiano, as "porosidades" e "fechamentos" que tais processos assumem frente à construção da identidade da docência e do sentir-se docente (Lahire, 2002).

Valorizar a complexidade das apropriações realizadas pelos docentes no interior do campo educacional e as movimentações dialógicas que nele subsistem, nos parece um potente dispositivo para revelar as possíveis implicações entre os desejos presentes na agenda reformista (SUS e Formação de Profissionais de Saúde ligados aos seus atributos ético-políticos) e a maneira como cada agente, a partir de sua trajetória de vida, se apropria de tais desejos e os transforma no cotidiano de seus fazeres pedagógicos (Saippa-Oliveira, Koifman, 2004). 
Esse reconhecimento pressupõe a busca da construção de uma nova cultura no interior das escolas, e, também, a necessidade de que os formuladores e "operacionalizadores" das agendas reformistas assumam a importância relativa dos saberes que têm potencial para transformarem em práticas e a maneira como estas produzem mediações frente às relações institucionais e normativas, presentes nas discussões do campo da saúde, que dão contornos aos processos pedagógicos nas escolas.

Compreender este jogo de posicionamentos e a complexidade da composição dos saberes e das práticas docentes, no interior do campo universitário, percebendo-as como expressão de tensões que se revelam nas contradições e as resistências presentes na diversidade de experiências que hoje ocorrem na formação em saúde em tempos de Sistema Único de Saúde (SUS), amplia, sobremaneira, a potência explicativa e de transformação dos processos de reestruturação dos processos formativos voltada a tais preceitos.

\section{Colaboradores}

Gilson Saippa Oliveira trabalhou na concepção, no delineamento e na redação do artigo. Lilian Koifman trabalhou na revisão crítica, construindo e elaborando a versão apresentada.

\section{Referências}

ARAUJO, E.C.; BATISTA, S.H.; GERAB, I.F. A produção científica sobre docência em saúde: um estudo em periódicos nacionais. Rev. Bras. Educ. Méd., v.35, n.4, p.486-92, 2011.

BATISTA, S.H. Aprendizagem, ensino e formação em saúde In: BATISTA, N.A.; BATISTA, S.H. (Orgs.). Docência em saúde: temas e experiências. São Paulo: Editora Senac, 2004. p.57-74.

BEHRENS, M.A. A formação pedagógica e os desafios do mundo moderno. In: MASSETO, M. (Org.). Docência na universidade. São Paulo: Papirus, 2000. p.57-68.

BORGES, C.M.F. O professor da educação básica e seus saberes profissionais. Araraquara: JM Editores, 2004.

BOURDIEU, P. Razões práticas sobre a teoria da ação. Campinas: Papirus, 2005.

Os usos sociais da ciência: por uma sociologia clínica do campo científico. São Paulo: Editora Unesp, 2004.

O conhecimento pelo corpo. In: . Meditações pascalianas. Rio de Janeiro: Bertrand do Brasil, 2001. p.157-98.

Homo academicus. Califórnia: Stanford University Press, 1988.

. Campo intelectual e projeto criador. In: POUILLON,J (Org.). Coletânea de artigos da Revista Les Temps Modernes, Paris, França, n.246. Problemas do Estruturalismo. Rio de Janeiro: Zahar Editores, 1968. p.105-46.

BOURDIEU, P.; WACQUANT, L. Una invitación a la sociología reflexiva. 2.ed. Buenos Aires: Siglo XXI, 2008.

BRANDT RIBEIRO, V.M. Uma pequena conversa sobre currículo, prática docente e teoria da ação comunicativa. Physis, v.9, n.2, p.99-116, 1999. 
BRANDT RIBEIRO, V.M. Pró-Saúde - Programa Nacional de Reorientação da Formação Profissional em Saúde (Pró-Saúde II). Brasília: MS, 2007. Disponível em:

<http://www.saude.gov.br/sgtes>. Acesso em: 12 abr. 2010.

Pró-Saúde - Programa Nacional de Reorientação da Formação Profissional em Saúde. Brasília: MS, 2005. Disponível em: <http://www.saude.gov.br/sgtes>. Acesso em: 23 jan. 2008.

Conselho Nacional de Saúde. 12. ${ }^{a}$ Conferência Nacional de Saúde. Conferência Sergio Arouca. Brasília, 7 a 11 de dezembro de 2003: relatório final. Brasília: Ministério da Saúde, 2004b. (Série D - Reuniões e Conferências). Disponível em:

<http://conselho.saude.gov.br/>. Acesso em: 12 abr. 2007.

Secretaria de Gestão do Trabalho e da Educação em Saúde. Departamento de Gestão da Educação na Saúde. Aprender-SUS: o SUS e os cursos de graduação da área da saúde. Brasília: MS, 2004a. Disponível em: <http:// www.saude.gov.br/sgtes>. Acesso em: 29 jan. 2008.

Políticas de formação e desenvol-vimento para o SUS: caminhos para a educação permanente em saúde. 2003. Disponível em: <http://portal.saude.gov.br/ saude/arquivos/pdf /pol_formacao_desenv.pdf>. Acesso em: 15 fev. 2007.

PROMED - Programa de Incentivo às Mudanças Curriculares para as Escolas Médicas. Brasília: MS, 2002.

BRASIL. Ministério da Saúde. 11ª Conferência Nacional de Saúde, Brasília 15 a 19 de dezembro de 2000. O Brasil falando como quer ser tratado: efetivando o SUS: acesso, qualidade e humanização na atenção à saúde com controle social: relatório final. Brasília: MS, 2001. (Série Histórica do CNS, n.2; Série D - Reuniões e Conferências, n.16). Disponível em: <http://conselho.saude.gov.br/>. Acesso em: 10 jun. 2003.

CECCIM, R.B. Onde se lê "Recursos humanos da saúde", leia-se "Coletivos organizados de produção da saúde: desafios para a educação". In: PINHEIRO, R.; MATTOS, R.A. (Orgs.). Construção social da demanda: direito à saúde, trabalho em equipe, participação e espaços públicos. Rio de Janeiro: Cepesc/UERJ, Abrasco, 2005. p.161-80.

CORTESÃO, L. Ser professor: um ofício em risco de extinção? São Paulo: Cortez, 2002.

COSTA, N.M.S.C. Formação pedagógica de professores de medicina. Rev. Latino-Am. Enferm., v.18, n.1, p.102-108, 2010.

CUNHA, M.I. Docência na universidade, cultura e avaliação institucional: saberes silenciados em questão. Rev. Bras. Educ., v.11, n.32, p.258-371, 2006.

DUBAR, C. A socialização construção das identidades sociais e profissionais. São Paulo: Martins Fontes, 2005.

ELIAS, N. Mudanças na balança nós-eu. In: ELIAS, N. (Org.). A sociedade dos indivíduos. Rio de Janeiro: Jorge Zahar, 1994. p.127-90.

FARIA, J.I.L.; CASAGRANDE, L.D.R. A educação para o século XXI e a formação do professor reflexivo na enfermagem. Rev. Latino-Am. Enferm., v.12, n.5, p.821-7, 2004.

FIORENTINI, D.; SOUZA JÚNIOR, A.J.S.; MELO, G.F.A. Saberes docentes: um desafio para acadêmicos e práticos. In: GERALDI, C.M.G.; FIORENTINI, D.; PEREIRA, E.M.A. (Orgs.). Cartografia do trabalho docente professor(a)-pesquisador(a). Campinas: Mercado das Letras, Associação de Leitura do Brasil, 2007. p.307-35.

HADDAD, A.E.; RISTOFF, D.; PASSARELLA, T. (Org.). A aderência dos cursos de graduação em Enfermagem, Medicina e Odontologia às Diretrizes Curriculares Nacionais. Brasília: MS, MEC, 2006. v.1.

HUBERMAN, M. O ciclo de vida profissional dos professores. In: NÓVOA, A. (Org.). Vidas de professores. 2.ed. Porto: Porto Editora, 2007. p.31-62. 
JAPIASSÚ, H. A crise nas ciências sociais. In: FAZENDA, I. (Org.). A pesquisa em educação e as transformações do conhecimento. 2.ed. Campinas: Papirus, 1997. p.75-86.

LAHIRE, B. Homem plural: os determinantes da ação. Petrópolis: Vozes, 2002.

LUCARELLI, E. Um desafio institucional: inovação e formação pedagógica do docente universitário. In: CASTANHO, S.; CASTANHO, M.E.L.M. (Orgs.). O que há de novo na Educação Superior do projeto pedagógico à prática transformadora. São Paulo: Papirus, 2000. p.61-74.

MOITA, M.C. Percursos de formação e de trans-formação. In: NÓVOA, A. (Org.). Vidas de professores. 2 ed. Porto: Porto Editora, 2007. p.111-40.

MOREIRA, A.F.B. Identidades em crise e práticas pedagógicas. In: VARANI, A.; FERREIRA, C.R.; PRADO, G.V.T. (Orgs.). Narrativas docentes: trajetórias de trabalhos pedagógicos. Campinas: Mercado das Letras, 2007. p.261-72.

MORIN, E. A ecologia das ideias. In: (Org.). O método 4. As idéias habitat, vida, costumes, organização. Porto Alegre: Sulina, 1998. p.17-136.

MOROSINI, M.C. Docência universitária e os desafios da realidade nacional. In: (Org.). Professor do ensino superior: identidade, docência e formação. Brasília: Instituto Nacional de Estudos e Pesquisas Educacionais, 2000. Disponível em: <http://www.inep.gov.br>. Acesso em: 25 ago. 2007.

NÓVOA, A. Os professores e as histórias da sua vida. In: professores. 2.ed. Porto: Porto Editora, 2007. p.11-30. (Org.). Vidas de Formação de professores e profissão docente. In: (Org.). Os professores e sua formação. Lisboa: Publicações Dom Quixote, 1997. p.15-33.

OLIVEIRA, G.S. Saberes e esquemas de ação docente em saúde coletiva. 2010: Tese (Doutorado) - Escola Nacional de Saúde Pública Sergio Arouca, Fundação Oswaldo Cruz, Rio de Janeiro, 2010.

OTERO RIBEIRO, E.C. Educação Permanente em Saúde. In: MARINS, J.J.N. et al. (Orgs.). Educação médica em transformação: instrumentos para a construção de novas realidades. Rio de Janeiro: Abem, Hucitec, 2004. p.285-303.

PIMENTA, S.G.; ANASTASIOU, L.G. Docência no ensino superior. São Paulo: Cortez, 2005. v.1.

RONZANI, T.M. A reforma curricular nos cursos de saúde: qual o papel das crenças? Rev. Bras. Educ. Med., v.31, n.1, p.38-43, 2007.

SAIPPA-OLIVEIRA, G.; KOIFMAN, L. Os docentes universitários: como transformar a formação? In: PINHEIRO, R.; SILVA JÚNIOR, A.G. (Orgs.). Cidadania do cuidado: o universal e o comum na integralidade das ações de saúde. 1.ed. Rio de Janeiro: Abrasco, Cepesc, UERJ, 2011. v.1. p.197-210.

Integralidade do currículo de medicina: inovar/transformar, um desafio para o processo de formação. In: MARINS, J.J.N. et al. (Orgs.). Educação médica em transformação: instrumentos para a construção de novas realidades. Rio de Janeiro: Abem, Hucitec, 2004. p.143-64.

SOUSA SANTOS, B. Da ideia de universidade à universidade de ideias. In: . Pela mão de Alice: o social e o político na pós-modernidade. São Paulo: Cortez, $\overline{1996 .}$ p.187-234.

TARDIF, M. Saberes docentes e formação profissional. 5.ed. Petrópolis: Vozes, 2005.

TARDIF, M.; LESSARD, C. O trabalho docente elementos para uma teoria da docência como profissão de interações humanas. 2.ed. Petrópolis: Vozes, 2005.

THERRIEN, J. Saber de experiência, identidade e competência profissional: como os docentes produzem sua profissão. Contexto Educ., v.12, n.48, p.15-21, 1997. 
O trabalho se propõe analisar as relações dos saberes que criam a identidade dos docentes da área da saúde e valorizar o entendimento das relações e posicionamentos sociais que imprimem marcas, no exercício da docência, como elementos que contribuem ou não para a efetivação das propostas de transformação dos processos de formação em saúde em curso, a partir dos condicionantes éticos e políticos do Sistema Único de Saúde (SUS). O reconhecimento de tais relações pressupõe a busca na construção de uma nova cultura no interior dos cursos de graduação em saúde, imprimindo importância aos saberes identitários docentes que, por inúmeras vezes, dão contornos aos processos pedagógicos universitários.

Palavras-chave: Formação em saúde. Sistema Único de Saúde. Campo científico. Saberes docentes. Processos pedagógicos universitários.

\section{A reflection on the multiple senses of healthcare teaching}

The aims of this study were to analyze the relationships among the fields of knowledge that create healthcare teachers' identity, and to place value on understanding the social relations and positions that mark out teaching practices as elements that may or may not contribute towards implementation of the current proposals for transforming the healthcare training processes, starting from the ethical and political parameters of the Brazilian National Health System (SUS). Recognition of such relationships makes the presupposition of seeking to construct a new culture within undergraduate healthcare courses, thereby placing importance on the knowledge that identifies teachers who, on very many occasions, give shape to university pedagogical processes.

Keywords: Healthcare training. National Health System. Scientific field. Teachers' knowledge. University pedagogical processes.

\section{Una reflexión sobre los múltiples sentidos de la docencia en salud}

Este trabajo se propone analizar las relaciones de los saberes que crean la identidad de los profesores del área de salud, valorar la comprensión de las relaciones y posiciones sociales que imprimen huellas en el ejercicio de la docencia como elementos que contribuyen o no en hacer efectivas las propuestas de transformaciones de los procesos de formación en salud en curso, a partir de los condicionantes éticos y políticos del Sistema Único de Salud Brasileño. El reconocimiento de tales relaciones presupone la búsqueda de la construcción de una nueva cultura en el interior de los cursos de grado en salud, imprimiendo importancia a los saberes que generan identidades docentes que, repetidas veces, dan forma a los procesos pedagógicos universitarios.

Palabras clave: Formación en salud. Sistema Único de Salud. Campo científico. Saberes docentes. Procesos pedagógicos universitarios. 